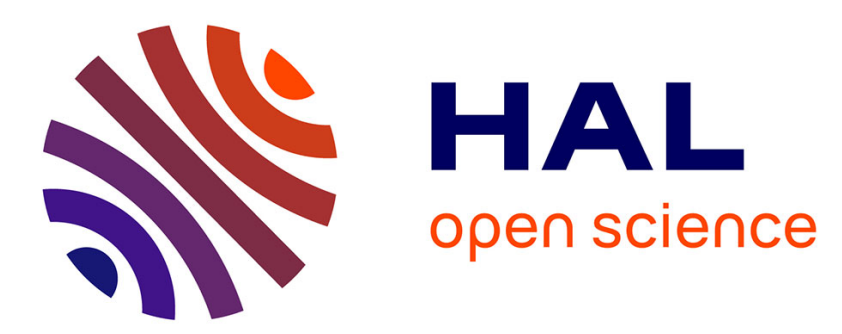

\title{
Footprint of temperature changes in the temperate and boreal forest carbon balance
}

Shilong Piao, P. Friedlingstein, Philippe Ciais, Philippe Peylin, B. Zhu, M. Reichstein

\section{- To cite this version:}

Shilong Piao, P. Friedlingstein, Philippe Ciais, Philippe Peylin, B. Zhu, et al.. Footprint of temperature changes in the temperate and boreal forest carbon balance. Geophysical Research Letters, 2009, 36, pp.L07404. 10.1029/2009GL037381 . bioemco-00450900

\section{HAL Id: bioemco-00450900 \\ https://hal-bioemco.ccsd.cnrs.fr/bioemco-00450900}

Submitted on 6 May 2021

HAL is a multi-disciplinary open access archive for the deposit and dissemination of scientific research documents, whether they are published or not. The documents may come from teaching and research institutions in France or abroad, or from public or private research centers.
L'archive ouverte pluridisciplinaire $\mathbf{H A L}$, est destinée au dépôt et à la diffusion de documents scientifiques de niveau recherche, publiés ou non, émanant des établissements d'enseignement et de recherche français ou étrangers, des laboratoires publics ou privés. 


\title{
Footprint of temperature changes in the temperate and boreal forest carbon balance
}

\author{
Shilong Piao, ${ }^{1}$ Pierre Friedlingstein, ${ }^{2}$ Philippe Ciais, ${ }^{2}$ Philippe Peylin, ${ }^{3}$ Biao Zhu, ${ }^{4}$ \\ and Markus Reichstein ${ }^{5}$ \\ Received 23 January 2009; revised 3 March 2009; accepted 11 March 2009; published 4 April 2009.
}

[1] In this study, we use net ecosystem productivity (NEP) measurement data across several forest sites and a simple conceptual model to investigate the linkage between temperature and NEP by considering either temperature change in the recent past or current mean annual temperature (MAT) as a forcing. After removing the effect of stand age, forest NEP is only weakly correlated with MAT. However, temperature changes during the period of 1980-2002 do explain a very significant fraction of the current spatial patterns of NEP, although the response of the terrestrial carbon balance to temperature changes varies with season. Changes in spring temperature having the highest correlation with annual NEP. We also show that temperature changes before the 1970s had a limited influence on the current NEP, and that the impact of recent temperature changes within the last decade on NEP are not strong enough to be observable. Overall, our analysis indicates not only that temperature changes in the recent past is one of the important drivers of today's forest carbon balance in the Northern Hemisphere, but also that the ongoing global warming will contribute significantly to the near-future evolution of the Northern Hemisphere carbon sink. A non-equilibrium framework must be taken into account when studying the impacts of temperature change on current or future forest net carbon balance. Citation: Piao, S., P. Friedlingstein, P. Ciais, P. Peylin, B. Zhu, and M. Reichstein (2009), Footprint of temperature changes in the temperate and boreal forest carbon balance, Geophys. Res. Lett., 36, L07404, doi:10.1029/2009GL037381.

\section{Introduction}

[2] In the past three decades, the global average temperature has increased at a maximum rate of $0.03^{\circ} \mathrm{C} \mathrm{yr}^{-1}$, reaching its highest value in the instrumental record [Intergovernmental Panel on Climate Change (IPCC), 2007]. The warming has directly and indirectly influenced almost all aspects of terrestrial carbon cycle processes and will continue to do so in this century [Randerson et al., 1999]. Thus, there is a compelling need to understand the response of ecosystem net carbon fluxes to temperature change across spatial and temporal scales.

\footnotetext{
${ }^{1}$ Department of Ecology, College of Urban and Environmental Science, Peking University, Beijing, China.

${ }^{2}$ LSCE, UMR1572, CEA, CNRS, Gif-sur-Yvette, France.

${ }^{3}$ Laboratoire de Biogéochimie Isotopique, Thiverval-Grignon, France.

${ }^{4}$ Department of Environmental Studies, University of California, Santa Cruz, California, USA.

${ }^{5}$ Max Planck Institute for Biogeochemistry, Jena, Germany.
}

Copyright 2009 by the American Geophysical Union. 0094-8276/09/2009GL037381
[3] Based on regional networks of eddy flux towers over temperate and boreal forests, previous analyses concluded that MAT strongly controls spatial gradients of Gross Primary Production (GPP) and Total Ecosystem Respiration (TER), but that MAT does not explain Net Ecosystem Productivity (NEP) gradients [Magnani et al., 2007; Reichstein et al., 2007]. An equally weak role of precipitation in explaining spatial gradients of NEP was also found [Magnani et al., 2007] when excluding water limited southern and Mediterranean forests. These results are not only at odds with a wealth of atmospheric and other data showing that year-toyear temperature shifts have a strong impact on short term variations in the terrestrial $\mathrm{C}$ balance [Randerson et al., 1999], but also crucial in evaluating global models of the terrestrial biosphere, because these models are using climate change and atmospheric $\mathrm{CO}_{2}$ fertilization as basic drivers of the current and future spatial patterns of carbon sinks and sources [Sitch et al., 2008].

[4] To investigate the impacts of temperature change on the carbon balance of terrestrial ecosystems, most previous studies have generally correlated annual NEP obtained from eddy-covariance data at various sites with mean annual temperature (MAT) [Magnani et al., 2007; Reichstein et al., 2007]. However, it is important to note that NEP is not determined by a single physiological process, but rather a result of the combined responses of photosynthetic and respiratory $\mathrm{CO}_{2}$ fluxes to changes in environmental conditions. Assuming that climate and atmospheric composition is in steady state equilibrium and there is an absence of external disturbances (e.g., fire), an ecosystem would theoretically reach equilibrium, photosynthesis being balanced by respiration (neglecting non- $\mathrm{CO}_{2}$ carbon emissions and lateral export fluxes through river), that is to say, net carbon exchange between terrestrial and atmosphere system would equal zero. This would happen across the globe, although temperature and precipitation vary over space. Any departure from such an asymptotic equilibrium needs therefore to be found in temporal changes in environmental conditions. Hence, we propose that predicting how temperature controls the spatial distribution of NEP must consider past temperature changes in addition to current temperature values.

[5] The primary purpose of this article is to prove that a non-equilibrium framework must be taken into account when studying the linkage between temperature and NEP. We develop a simple conceptual model to qualitatively highlight the temporal component of this linkage. Accordingly, we do not attempt to provide a realistic quantitative assessment of the role of temperature in the terrestrial carbon cycle. To meet our goal, we reanalyzed NEP measurements corrected for age effects from 20 temperate and boreal forest sites as described by Magnani et al. 
[2007], using observed historical temperature data [Mitchell and Jones, 2005].

\section{Methods and Datasets}

[6] Annual eddy-covariance NEP measurements at 20 temperate and boreal forest sites (8 temperate forest sites and 12 boreal forest sites over the region between $43.2^{\circ} \mathrm{S}$ to $60.7^{\circ} \mathrm{N}$ ) used in this study are the same as those used by Magnani et al. [2007] (hereinafter referred to as MA07). Confounding effects of forest age have been subtracted by MA07 from short-term eddy-covariance NEP records, through averaging NEP over the entire rotation period with an age-dependent effect on light use efficiency and allocation. Thus, this age-corrected mean NEP dataset allows us to explore the effects of historical temperature change on ecosystem $\mathrm{C}$ balance. Monthly temperature reconstructions, with a spatial resolution of 0.5 degree, are from the Climatic Research Unit (CRU) dataset, School of Environmental Sciences, University of East Anglia, U.K. [Mitchell and Jones, 2005]. As we do not focus on interannual variability, the change in temperature $(\delta \mathrm{T})$ is expressed here by multiplying the linear trend of temperature $(\mathrm{T})$ by the length of the period considered to impact NEP.

[7] Gradients of productivity and respiration in response to environmental change and disturbance will jointly lead to a net absorption or release of carbon, which appears to be the main determinant of the spatial patterns of NEP [Luyssaert et al., 2007]. Without considering the effects of disturbance, NEP can be modeled by the difference between net primary productivity (NPP, $\mathrm{gC} \mathrm{m}^{-2} \mathrm{yr}^{-1}$ ) input and heterotrophic respiration output described by soil organic $\mathrm{C}$ pool $\left(\mathrm{C}_{\mathrm{S}}, \mathrm{gC}\right.$ $\mathrm{m}^{-2}$ ) divided by its Mean Residence Time ( $\mathrm{t}_{\mathrm{e}}, \mathrm{yr}$ ) (equation 1).

$$
N E P(t)=C(t)-C(t-1)=N P P(t)-\frac{C_{S}(t-1)}{t_{e}}
$$

where $\mathrm{C}$ is the total $\mathrm{C}$ storage in the terrestrial ecosystems. The efficiency of plants to transform incoming sunlight into NPP (light use efficiency) is generally reduced when plants are exposed to temperature differing from the optimum temperature [Field et al., 1995]. Here, we use the formulation of the CASA model [Field et al., 1995] to describe the temperature dependence of NPP by a function $\mathrm{S}_{\mathrm{T}}$ which peaks around an optimal growth temperature $\mathrm{T}_{\mathrm{opt}}$ (equation 2); for temperate and boreal forest, $\mathrm{T}_{\mathrm{opt}}=20^{\circ} \mathrm{C}$ ). The optimal value of NPP in absence of temperature limitation, $\mathrm{NPP}_{\text {opt }}\left(1018 \mathrm{gC} \mathrm{m}^{-2} \mathrm{yr}^{-1}\right.$ at $\left.20^{\circ} \mathrm{C}\right)$ is defined from the Luyssaert et al. [2007] ecological database.

$$
\begin{aligned}
N P P(t)= & N P P_{\text {opt }} \times S_{T}(t) \\
= & N P P_{\text {opt }} \times 1.1814 /\left\{1+e^{\left[0.2\left(T_{\text {opt }}-10-M A T(t)\right]\right.}\right\} \\
& /\left\{1+e^{\left[0.3\left(-T_{\text {opt }}-10+M A T(t)\right]\right.}\right\} \\
= & 1018 \times 1.1814 /\left\{1+e^{[0.2(10-M A T(t)]}\right\} \\
& /\left\{1+e^{[0.3(-30+M A T(t)]}\right\}
\end{aligned}
$$

where $\operatorname{MAT}(t)$ is the mean annual temperature for a given year $t$. The mean residence time of soil organic carbon in temperate and boreal forests, generally takes values between
20-60 years [Bird et al., 1996]. Here, we will assume $t_{e}=$ 40 years when MAT $=0^{\circ} \mathrm{C}$ and a decomposition rate $\left(1 / \mathrm{t}_{\mathrm{e}}\right)$ that exponentially increases with rising $\mathrm{MAT}\left(\mathrm{Q}_{10}\right.$ formulation with $\mathrm{Q}_{10}=2$ ), as given by equation (3) below.

$$
\frac{1}{t_{e}(t)}=\frac{1}{40} \times Q_{10}^{\left(\frac{M A T(t)}{10}\right)}=\frac{1}{40} \times 2^{\left(\frac{M A T(t)}{10}\right)}
$$

Accordingly, equation (1) can be further expressed as a function of MAT (equation (4)).

$$
\begin{aligned}
N E P(t)= & 1018 \times 1.1814 /\left\{1+e^{[0.2(10-M A T(t)]}\right\} \\
& /\left\{1+e^{[0.3(-30+M A T(t)]}\right\}-C_{S}(t-1) \times\left(\frac{1}{40} \times 2^{\left(\frac{M A T(t)}{10}\right)}\right)
\end{aligned}
$$

The conceptual model defined by equation (4) does not account for different sensitivities of NEP to seasonal temperature changes [Randerson et al., 1999; Piao et al., 2008], and makes the simplification that forest carbon balance is only driven by a single climate variable, here temperature. One must keep in mind that other factors such as precipitation, $\mathrm{N}$-deposition or rising atmospheric $\mathrm{CO}_{2}$ as well as changes in forest management and natural disturbance rates and intensity also likely play a role in controlling NEP [Magnani et al., 2007].

\section{Results}

[8] Figure 1 illustrates the relationships between NEP measurement data for 20 temperate and boreal forest sites and corresponding MAT and change in MAT ( $\delta$ MAT) and seasonal temperatures during 1980-2002. Only a relatively weak linear (or exponential) correlation between mean annual NEP and MAT can be seen in Figure 1a, which is consistent with the results of Magnani et al. [2007]. A similar proportion of the spatial variance of mean annual NEP can be explained by $\delta$ MAT (Figure 1b). However, when comparing mean annual NEP with changes in spring (March to May) temperature from 1980 to 2002, we find a very high correlation (Figure 1d). If the data from the four Siberian sites (latitude $60.43^{\circ} \mathrm{N}$; longitude $89.08^{\circ} \mathrm{E}$ ) are excluded from the regression, about $84 \%$ of the cross-site variation in mean annual NEP is explained by the simple exponential model equation using $\delta \mathrm{T}_{\text {Spring }}$ as a predictor variable. The relatively small magnitude of mean annual NEP at the Siberian sites may be related to the decreasing temperature in both June [Panyushkina et al., 2003] and August (Figure 1j) over the last two decades and the relatively late growing season start driven by low spring temperature (average temperature from March to May is only about $-2.1^{\circ} \mathrm{C}$ ). Indeed, the $\mathrm{R}^{2}$ value is estimated at 0.59 and 0.63 for the linear and exponential relationships between mean annual NEP and $\delta \mathrm{T}_{\text {August }}$ (Figure 1j). A negative correlation between NEP and autumn (September to November) temperature change $\left(\delta \mathrm{T}_{\text {Autumn }}\right)$ is also observed across these sites, suggesting that autumn warming does not benefit net carbon uptake in northern temperate and boreal forests (Figure 1h).

[9] We also analyzed the linear correlation coefficients $\left(\mathrm{R}^{2}\right)$ between NEP at 16 temperate and boreal forest sites (still excluding the four Siberian sites) and corresponding $\delta \mathrm{T}$ for the different periods of $1950-2002,1960-2002$, 

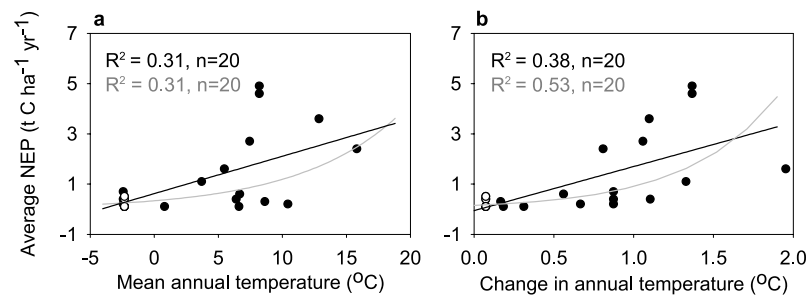

1970-2002, 1980-2002, and 1990-2002. As shown in Figure 2, the maximum $\mathrm{R}^{2}$ between NEP and $\delta \mathrm{T}$ spatial gradients occurs when considering spring temperature change $\left(\delta \mathrm{T}_{\text {Spring }}\right)$ integrated either since 1970 or since 1980. In contrast, the $\mathrm{R}^{2}$ between NEP and $\delta \mathrm{T}$ for the periods of 1950-2002, 1960-2002 and 1990-2002 is relatively low (Figure 2 ).

[10] Finally, we apply the conceptual model of equation (4) to explain the results found above. We evaluated how NEP, initially in steady-state equilibrium with climate $(t=1)$, i.e., $\mathrm{C}(0)=\mathrm{NPP}_{\text {eq }} \times \mathrm{t}_{\mathrm{e} \text {-eq }}$ with $\mathrm{NPP}_{\text {eq }}$ and $\mathrm{t}_{\mathrm{e}-\mathrm{eq}}$ defining the equilibrium values, responds transiently (1) to a one-time temperature increase (Figure 3a), and (2) to a gradual linear warming (Figure $3 \mathrm{~b}$ ). Figure 3 clearly illustrates that the value of NEP at time $t$ is dependent not only on MAT, but also on the magnitude of the prescribed stepwise or gradual temperature change, defined by $[\operatorname{MAT}(\mathrm{t})-\mathrm{MAT}(1)]$. As an example, for the forest growing at a $5^{\circ} \mathrm{C}$ MAT, 30 years of gradually linear increase in temperature with the magnitude of $0.05^{\circ} \mathrm{C} \mathrm{yr}^{-1}$ and $0.1^{\circ} \mathrm{C} \mathrm{yr}^{-1}$ would produce NEP by $24 \mathrm{gC}$ $\mathrm{m}^{-2} \mathrm{yr}^{-1}$ and $48 \mathrm{gC} \mathrm{m}^{-2} \mathrm{yr}^{-1}$, respectively (Figure $3 \mathrm{~b}$ ). This example highlights the contribution of temperature change to NEP. Thus, past temperature changes should not be ignored in explaining the distribution and magnitude of current NEP.

\section{Discussions}

[11] The ability of past temperature changes to explain the current spatial pattern of NEP however depends on the length of the forcing period (Figure 2). The maximum $\mathrm{R}^{2}$ between NEP and $\delta \mathrm{T}$ integrated during the period of 1950 $2002(45 \%)$ and 1960-2002 (42\%) is much lower than that during the period of 1970-2002 (69\%) and 1980-2002 (73\%). This implies that $\delta$ T occurred before the 1970 s has a limited influence on the current spatial pattern of forest NEP. This small response may be related to the relatively long forcing period length compared with the turnover time. As shown by Figure 3a, the effect of a one-time temperature increase on NEP diminished over time. Based on the simple conceptual model (equation (4)), we estimated that when MAT equals $5^{\circ} \mathrm{C}$, a one-time temperature increase by $1^{\circ} \mathrm{C}$ resulted in a decrease in NEP of about 70\% (from $26 \mathrm{gC}$

(a) The spatial correlation between mean ann NEP and mean annual temperature (MAT), (b) change in mean annual temperature ( $\delta \mathrm{MAT})$, (c) spatial correlation between mean annual NEP and mean spring temperature, (d) change in spring (March to May) temperature $\left(\delta \mathrm{T}_{\text {Spring }}\right)$, (e) spatial correlation between mean annual NEP and mean summer temperature, (f) change in summer (June to August) temperature $\left(\delta \mathrm{T}_{\text {Summer }}\right)$, $(\mathrm{g})$ spatial correlation between mean annual NEP and mean autumn temperature, (h) change in autumn (September to November) temperature $\left(\delta \mathrm{T}_{\text {Autumn }}\right)$, (i) spatial correlation between mean annual NEP and mean August temperature, and (j) change in August temperature $\left(\delta \mathrm{T}_{\text {August }}\right)$ for the 20 temperate and boreal forest sites of Magnani et al. [2007] from 1980 to 2002. The change in temperature from 1980 to 2002 is expressed by multiplying the liner trend in temperature by 22 . White circles indicate the four Siberian sites (latitude $60.43^{\circ} \mathrm{N}$; longitude $89.08^{\circ} \mathrm{E}$ ) [Magnani et al., 2007, Table 1] where June and August temperature decreased from 1980 to 2002. Both linear (black) and exponential (gray) models are used in the regression analysis to compare with the analysis of Magnani et al. [2007].

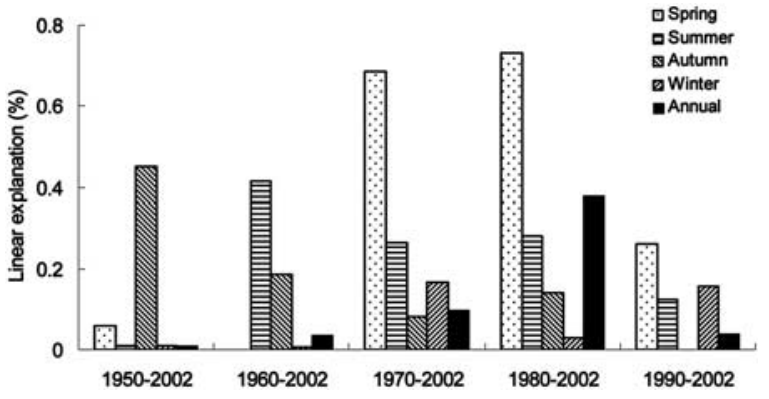

Figure 2. The linear spatial correlation coefficients $\left(\mathrm{R}^{2}\right)$ of seasonal temperature change during the five different periods $(1950-2002 ; 1960-2002 ; 1970-2002 ; 1980-$ 2002; 1990-2002) with mean annual NEP for the 20 temperate and boreal forest sites of Magnani et al. [2007]. In order to compare with Figure 1, Siberian sites (latitude $60.43^{\circ} \mathrm{N}$; longitude $89.08^{\circ} \mathrm{E}$ ) were not used in the analysis. 

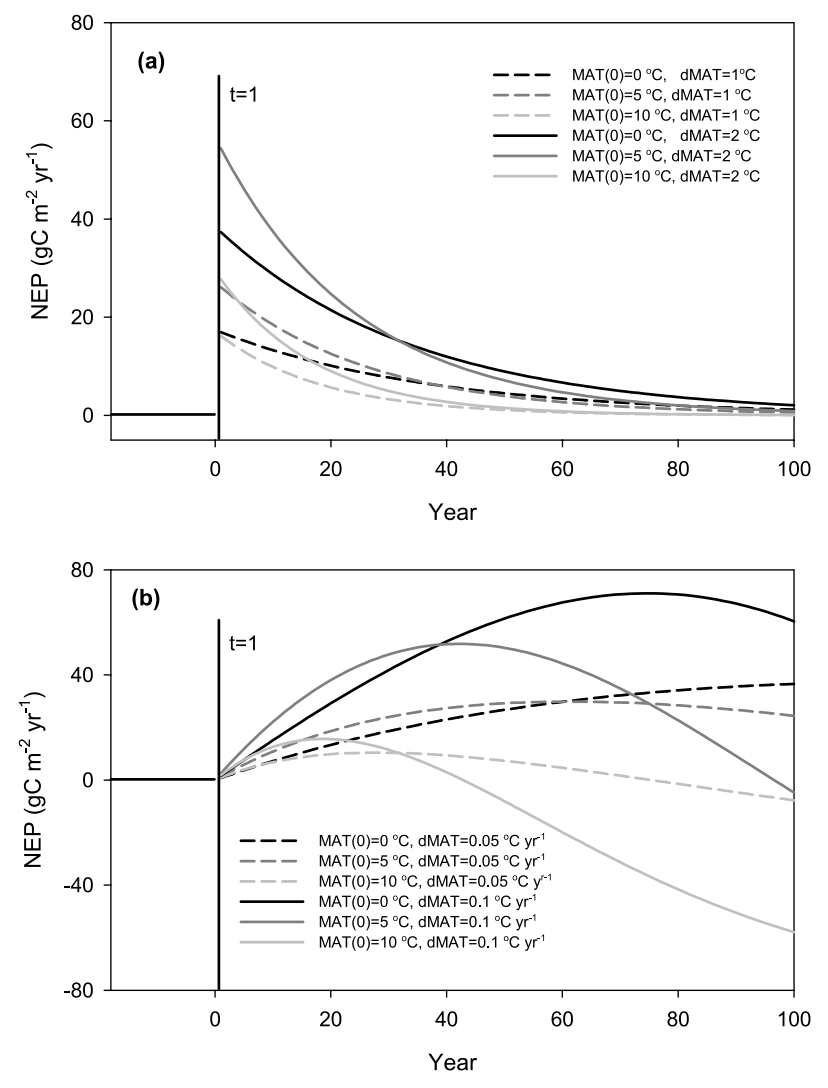

Figure 3. The response of NEP for the forest under initial equilibrium $\left(\operatorname{MAT}(0)=0,5,10^{\circ} \mathrm{C}\right)$ to the different magnitudes of (a) one-time temperature increase $\left(\delta \mathrm{MAT}=1\right.$ and $\left.2^{\circ} \mathrm{C}\right)$ and (b) gradually linear increase in temperature $(\delta \mathrm{MAT}=0.05$ and $0.1^{\circ} \mathrm{C} \mathrm{yr}^{-1}$ ) based on equation (4). Note that the simplified equation (equation (4)) does not take into account different roles of seasonal temperature change on NEP.

$\mathrm{m}^{-2} \mathrm{yr}^{-1}$ to $8 \mathrm{gC} \mathrm{m}^{-2} \mathrm{yr}^{-1}$ ) during the first 30 years (Figure 3a). At face value, if the stepwise temperature change is too recent, it will not yet have an discernable impact on NEP gradients. For instance, the spatial correlation between forest NEP and the corresponding $\delta \mathrm{T}$ since the 1990s is not strong enough to be observable (Figure 2).

[12] Our conceptual model results also suggest that the current forest capacity to act as a carbon sink can not persist under continued global warming (see Figure $3 b$ ), even without considering increased soil aridity driven by rising temperature. When MAT equals $10^{\circ} \mathrm{C}$, for example, the simple conceptual model (equation (4)) derived forest carbon sink is strengthened during the first 29 years with a gradual increase in MAT by $0.05^{\circ} \mathrm{C} \mathrm{yr}^{-1}$. After 29 years, a weakening carbon sink and eventually a carbon source was estimated by the model (Figure $3 \mathrm{~b}$ ), since the previous carbon storage accumulation and continuously rising temperature together result in a larger magnitude of increase in heterotrophic respiration than that in NPP. The conceptual model analysis thus supports the results from a variety of more complex process-based terrestrial ecosystem models, which projected that terrestrial carbon sinks should peak by around 2050 and then diminish towards the end of the $21 \mathrm{st}$ century [Sitch et al., 2008].
[13] Our analysis of NEP data also indicates that the effects of temperature change on NEP are season-dependent [Randerson et al., 1999; Piao et al., 2008], implying that at longer time scales, our ability to accurately model carbon fluxes is partly constrained by our understanding of how seasonal temperature might vary over time. Several studies have suggested that rising spring temperature has caused earlier growing season start and spring thaw, which led to a larger enhancement of vegetation productivity than soil respiration due to the relatively abundant solar radiation and moisture conditions in spring [Barr et al., 2004]. Accordingly, rising spring temperature can lead to an increase in net carbon uptake of temperate and boreal forest ecosystems, which is further supported by the positive relationship between annual NEP and spring temperature change presented in this study. Our results suggest that spring warming can explain a high percentage of the spatial variance of NEP $\left(\mathrm{R}^{2}=0.84\right)$ in our dataset. The effect of $\delta \mathrm{T}_{\text {Spring }}$ is comparable to that of $\mathrm{N}$ deposition $\left(\mathrm{R}^{2}=0.79\right)$ found by Magnani et al. [2007]. Multiple linear regression analysis of NEP $\left(\mathrm{gC} \mathrm{m}^{-2} \mathrm{yr}^{-1}\right)$ against spring temperature $\left(\delta \mathrm{T}_{\text {Spring }},{ }^{\circ} \mathrm{C}\right)$ change and $\mathrm{N}$-deposition $(\mathrm{dN}, \mathrm{Kg})(\mathrm{NEP}=$ $\left.-14+19 \times \delta \mathrm{T}_{\text {Spring }}+37 \times \mathrm{dN} ; \mathrm{R}^{2}=0.86, \mathrm{P}<0.001\right)$ further suggests that the increase in annual NEP associated with rising spring temperature is approximately $19 \mathrm{gC} \mathrm{m}^{-2}$ $\mathrm{yr}^{-1}{ }^{\circ} \mathrm{C}^{-1}$, while the NEP increase associated with $\mathrm{N}$ deposition is about $37 \mathrm{gC} \mathrm{m}^{-2} \mathrm{yr}^{-1}$ per $\mathrm{kg}$ of $\mathrm{N}$ wet deposition. In contrast, we found that the spatial distribution of NEP is negatively correlated with autumn temperature change over the past two decades. This agrees well with previous results derived from interannual variations of eddy-covariance flux measurements and atmospheric $\mathrm{CO}_{2}$ seasonal cycle, showing that warm autumns accelerate carbon loss from northern ecosystems because of a higher sensitivity of respiration to temperature compared to photosynthesis [Piao et al., 2008].

[14] Recently, Luyssaert et al. [2008] have found that oldgrowth forests currently sequester carbon, which conflicts with the hypothesis of old-growth forests carbon neutrality suggested by Odum [1969]. It should be noted that the current climate and atmospheric composition are not in steady state equilibrium, and the old-growth forests ecosystems are in the process of a transitional phase in response to changing climate and $\mathrm{CO}_{2}$. For example, Dhôte and Hervé [2000] have suggested a faster growth of forest related to climate trends, while Mantgem et al. [2009] have found widespread increase of tree mortality rates in old growth forests of the Western United States over the last few decades. These results suggest that a non-equilibrium framework must be taken into account for understanding the mechanisms of climate-driven carbon sinks and sources. A non-equilibrium conceptual framework should help us to explain why oldgrowth forests intriguingly sequester carbon and seem to be moving away from equilibrium.

\section{Conclusions}

[15] To our knowledge, the present study is the first attempt to examine and report the linkage between spatial patterns of historical temperature change and carbon sinks and sources. We conclude from our re-analysis of agecorrected NEP data at site-scale that past temperature 
changes integrated over 20-30 years significantly influence the current magnitude of forest carbon sink, certainly in addition to other factors, such as fertilization by increasing atmospheric $\mathrm{CO}_{2}$ [Piao et al., 2006], nitrogen deposition [Magnani et al., 2007], and re-growth of forests harvested in the early and middle parts of the 20th century [IPCC, 2007; Ciais et al., 2008]. Further studies based on the combination of global monitoring with ongoing experimental data acquisition, long-term $\mathrm{C}$ flux records, $\mathrm{C}$ pool changes measurements, and modeling are needed to reliably separate the relative contribution of each factor to current spatio-temporal patterns of $\mathrm{C}$ sink/source of temperate and boreal forests.

[16] Acknowledgments. S. L. P. wishes to thank F. Magnani for helpful comments and discussions. This study was supported by the Foundation for the Author of National Excellent Doctoral Dissertation of PR China (FANEDD-200737) and the EC funded projects ENSEMBLES (GOCE-CT-2003-505539), CARBOEUROPE IP (GOCE-CT-2003505572).

\section{References}

Barr, A. G., T. A. Black, E. H. Hogg, N. Kljun, K. Morgenstern, and Z. Nesic (2004), Inter-annual variability in the leaf area index of a boreal aspen-hazelnut forest in relation to net ecosystem production, Agric. For. Meteorol., 126, 237-255.

Bird, M. I., A. R. Chivas, and J. Head (1996), A latitudinal gradient in carbon turnover times in forest soils, Nature, 381, 143-145.

Ciais, P., et al. (2008), Carbon accumulation in European forests, Nat. Geosci., 1, 425-429.

Dhôte, J.-F., and J.-C. Hervé (2000), Productivity changes in four sessile oak forests since 1930: A stand-level approach, Ann. For. Sci., 57, 651-680.

Field, C. B., J. T. Randerson, and C. M. Malmstrom (1995), Global net primary production: Combining ecology and remote sensing, Remote Sens. Environ., 51, 74-88.

Intergovernmental Panel on Climate Change (IPCC) (2007), Climate Change 2007: The Physical Science Basis. Contribution of Working Group I to the Fourth Assessment Report of the Intergovernmental Panel on Climate Change, edited by S. Solomon et al., Cambridge Univ. Press, Cambridge, U. K.
Luyssaert, S., et al. (2007), $\mathrm{CO}_{2}$ balance of boreal, temperate, and tropical forests derived from a global database, Global Change Biol., 13, $2509-2537$

Luyssaert, S., et al. (2008), Old-growth forests as global carbon sinks, Nature, $455,213-215$.

Magnani, F., et al. (2007), The human footprint in the carbon cycle of temperate and boreal forests, Nature, 447, 848-850.

Mantgem, P. J., et al. (2009), Widespread increase of tree mortality rates in the western United States, Science, 323, 521-524.

Mitchell, T. D., and P. D. Jones (2005), An improved method of constructing a database of monthly climate observations and associated highresolution grids, Int. J. Climatol., 25, 693-712.

Odum, E. P. (1969), The strategy of ecosystem development, Science, 164, $262-270$

Panyushkina, I. P., M. K. Hughes, E. A. Vaganov, and M. Munro (2003), Summer temperature in northeastern Siberia since 1642 reconstructed from tracheid dimensions and cell numbers of Larix cajanderi, Can. J. For. Res., 33, 1905-1914.

Piao, S., P. Friedlingstein, P. Ciais, L. Zhou, and A. Chen (2006), Effect of climate and $\mathrm{CO}_{2}$ changes on the greening of the Northern Hemisphere over the past two decades, Geophys. Res. Lett., 33, L23402, doi:10.1029/ 2006GL028205.

Piao, S., et al. (2008), Net carbon dioxide losses of northern ecosystems in response to autumn warming, Nature, 451, 49-52.

Randerson, J. T., C. B. Field, I. Y. Fung, and P. P. Tans (1999), Increases in early season ecosystem uptake explain recent changes in the seasonal cycle of atmospheric $\mathrm{CO}_{2}$ at high northern latitudes, Geophys. Res. Lett., 26, 2765-2768.

Reichstein, M., et al. (2007), Determinants of terrestrial ecosystem carbon balance inferred from European eddy covariance flux sites, Geophys. Res. Lett., 34, L01402, doi:10.1029/2006GL027880.

Sitch, S., et al. (2008), Evaluation of the terrestrial carbon cycle, future plant geography and climate-carbon cycle feedbacks using five Dynamic Global Vegetation Models (DGVMs), Global Change Biol., 14, 2015-2039.

P. Ciais and P. Friedlingstein, LSCE, UMR1572, CEA, CNRS, L'Orme des Merisiers Bat. 709, F-91191 Gif-sur-Yvette, France.

P. Peylin, Laboratoire de Biogéochimie Isotopique, Bat EGER, F-78859 Thiverval-Grignon CEDEX, France.

S. Piao, Department of Ecology, College of Urban and Environmental Science, Peking University, Beijing 100871, China. (slpiao@pku.edu.cn)

M. Reichstein, Max Planck Institute for Biogeochemistry, P.O. Box 100164, D-07701 Jena, Germany.

B. Zhu, Department of Environmental Studies, University of California, Santa Cruz, CA 95064, USA. 